\title{
Risicobeoordeling en beleidsopties van fumonisines in aanvullende voeding op basis van maïs in Tanzania
}

\section{Martin Epafras Kimanya}

Promotoren: Johan Van Camp, Patrick Kolsteren

Vakgroep Voedselveiligheid en Voedselkwaliteit, Universiteit Gent

Openbare verdediging: 17 juni 2008

Net zoals in andere Afrikaanse landen, vertonen peuters in Tanzania een groei achterstand bij de overstap van borstvoeding naar overgangsvoeding. Moeders in Tanzania gebruiken maïs als een belangrijke ingrediënt voor de bereiding van deze overgangsvoeding. Maïs blijkt in veel gevallen gecontamineerd te zijn met mycotoxinen, zoals fumonisinen. De blootstelling aan deze toxinen zou de reeds ernstige gevallen van kinderziekten in de rurale gebieden van Tanzania nog verder verergeren. De doelstellingen van dit onderzoek waren: inzicht bekomen met betrekking tot de contaminatie van maïs die door de gezinnen zelf wordt verbouwd en van op maïs gebaseerde overgangsvoeding in Tanzania; de maïsinname van peuters inschatten; het verband onderzoeken tussen blootstelling aan fumonisinen en groeiachterstand bij peuters en deze data gebruiken bij het opstellen van een risicobeoordeling van fumonisinen in overgangsvoeding teneinde strategieën te ontwikkelen om de blootstelling van peuters aan fumonisinen in Tanzania terug te dringen.

In 2005 werd een inleidend onderzoek uitgevoerd in 120 huishoudens met betrekking tot de fumonisinecontaminatie van lokaal verbouwde maïs. Uit de vier belangrijkste mais producerende regio's van Tanzania (Iringa, Kilimanjaro, Ruvuma en Tabora) werden telkens 30 huishoudens geselecteerd. Naast de stalen werd ook informatie ingewonnen met betrekking tot de praktijken die toegepast worden bij het gebruik van de maïs voor voedingsdoeleinden. Dit om te kunnen inschatten of deze een impact hadden op de blootstelling aan fumonisinen en aflatoxinen. Omdat uit dit inleidend onderzoek bleek dat in de Kilimanjaro regio het hoogste risico bestond om aan fumonisinen blootgesteld te worden, werd deze regio geselecteerd voor verder onderzoek. Van mei tot juni 2006 werd net geoogste maïs bemonsterd bij 67 gezinnen in het Rombo district van de Kilimanjaro regio. Tegelijkertijd werd informatie ingewonnen met betrekking tot de toegepaste praktijken inzake maïsteelt, sortering en opslag. Vijf maanden later werd de opgeslagen maïs bij dezelfde gezeinnen bemonsterd voor fumonisine analyse. In de periode van juli tot september van dit jaar werden bovendien in dit district 6 maand oude peuters gerekruteerd voor de studie met betrekking tot het verband tussen fumonisineblootstelling en verschillende antropologische parameters. De lengte en het gewicht van elk kind werden gemeten bij een leeftijd van 6 maanden en deze metingen werden herhaald bij elk kind na het bereiken van de leeftijd van I jaar. Voor elk kind werd bij de leeftijd van 6 tot 8 maanden een consumptiepeiling uitgevoerd met betrekking tot de consumptie en 
samenstelling van de aanvullende voeding aan de hand van een 24-uursvoedingsnavraag. In dit consumptieonderzoek werd gepeild naar het type en de hoeveelheden van overgangsvoeding die geconsumeerd werden. Daarnaast werden er stalen genomen van het kant-en-klare maïsmeel dat gebruikt werd om de overgangsvoeding te bereiden. De consumptiedata werden in een databank gebracht en verwerkt, wat toeliet om in te schatten hoeveel maïs elke peuter consumeerde. De fumonisineconcentratie in het bemonsterde maïsmeel werd bepaald middels een HPLC-analyse gekoppeld aan een fluorescentie detectie.

In hoofdstuk 2 worden de resultaten voorgesteld met betrekking tot de fumonisineen aflatoxinegehaltes van de onderzochte maïsmonsters die werden genomen in de vier betrokken regio's van Tanzania, namelijk Iringa, Kilimanjaro, Tabora en Ruvuma. Van de 120 geanalyseerde stalen bleken er $52 \%$ fumonisinen te bevatten met concentraties die opliepen tot $\mathrm{Ir}, 048 \mu \mathrm{g} / \mathrm{kg}$ (mediaan, $363 \mu \mathrm{g} / \mathrm{kg}$ ). Vijftien percent van de stalen overschreden de grens van $\mathrm{I} 000 \mu \mathrm{g} / \mathrm{kg}$, wat in verschillende landen de maximale limiet is voor maïs bestemd voor humane consumptie. Aflatoxinen werden in $18 \%$ van de onderzochte monsters teruggevonden en de concentraties liepen op tot $158 \mu \mathrm{g} / \mathrm{kg}$ (mediaan, $24 \mu \mathrm{g} / \mathrm{kg}$ ). Twaalf percent van de onderzochte monsters overschreden de Tanzaniaanse maximale limiet voor totaal aflatoxinegehalte, die $10 \mu \mathrm{g} / \mathrm{kg}$ bedraagt. Aflatoxinen kwamen samen met fumonisinen voor in $12 \%$ van de onderzochte monsters. In de monsters afkomstig van de Kilimanjaro regio werden relatief gezien meer stalen

teruggevonden die met fumonisinen gecontamineerd waren, terwijl in de Tabora regio relatief meer stalen gecontamineerd bleken met aflatoxinen. Vijftig huishoudens gaven toe dat ze beschadigde of beschimmelde maïs consumeerden. Ondanks het feit dat alle gezinnen een risico liepen om blootgesteld te worden aan fumonisinen en aflatoxinen door de consumptie van maïs, werd aangetoond dat de gezinnen die beschadigde of beschimmelde maïs consumeerden, werden blootgesteld aan een beduidend hoger risico. Meer dan $89 \%$ van de onderzochte gezinnen in de Kilimanjaro regio consumeerden niet gepelde maïs (Dona). Op basis van de contaminatie data van de maïs bemonsterd in de Kilimanjaro regio en de plaatselijke gewoonte om de maïs onder de vorm van Dona te consumeren, kon besloten worden dat de gezinnen in deze regio het hoogste risico hadden om blootgesteld te worden aan fumonisinen.

Op een deterministische wijze werd de fumonisineblootstelling bij volwassen individuen in elk van de 120 onderzochte huishoudens ingeschat op basis van de bekomen fumonisinecontaminatie data voor elk specifiek gezin en de gemiddelde maïsconsumptie van $77 \mathrm{I} \mathrm{g} /$ persoon/dag zoals deze wordt aanbevolen door het Tanzaniaanse Centrum voor Levensmiddelen en Voeding (TFNC, Tanzanian Food and Nutrition Centre). Er werd ook uitgegaan van de actuele gemiddelde Tanzaniaanse consumptie data die 129 tot 356 $\mathrm{g} /$ persoon/dag bedraagt, afhankelijk van de geconsulteerde bron.

De resultaten van deze blootstellingsinschatting worden gerapporteerd en besproken in hoofdstuk 3. De resultaten toonden aan dat de fumonisineblootstelling bij volwassenen in $38 \%$ van de onderzochte gezinnen de PMTDI van $2 \mu \mathrm{g} / \mathrm{kg}$ lichaamsgewicht overschreed. Indien wordt uitgegaan van de laagst gerapporteerde maïsconsumptie van 
129 g/persoon/dag, bleek nog altijd $16 \%$ van de onderzochte personen de PMTDI te overschrijden. Om een te hoge blootstelling aan fumonisinen in de onderzochte rurale gebieden van Tanzania te vermijden bleek het noodzakelijk om de contaminatieniveaus in maïs terug te dringen tot $\mathrm{I} 55 \mathrm{\mu g}$ fumonisine/ $\mathrm{kg}$ maïsmeel.

In hoofdstuk 4 worden de resultaten van de vervolgstudie, die werd uitgevoerd in het Rombo district gelegen in de Kilimanjaro regio van Tanzania, voorgesteld en besproken. Deze vervolgstudie betrof een onderzoek bij 67 gezinnen. Vierentwintig van de 67 onderzochte stalen van ongesorteerde maïs die bemonsterd werd bij middelgrote landbouwers, bleken fumonisinen (FBI+FB2) te bevatten in concentraties gaande van 94 tot 2I $667 \mu \mathrm{g} / \mathrm{kg}$ (mediaan $783 \mu \mathrm{g} / \mathrm{kg}$ ). Het totale gehalte aan fumonisinen bleek in II van de onderzochte monsters de grens van $1000 \mu \mathrm{g} / \mathrm{kg}$ te overschrijden, hetgeen in de EU en vele andere landen het maximum toelaatbare gehalte is van maïs bestemd voor humane consumptie. In meer dan $90 \%$ van de gevallen werd maïs tezamen met andere gewassen verbouwd, werden pesticiden gebruikt tijdens het telen van de maiis maar werd geen rotatieteelt toegepast. Er kon geen significant verband teruggevonden worden tussen de teeltpraktijken en het voorkomen van fumonisinen in de maïs ( $p>0,05)$. Wel kon een significant verband worden aangetoond tussen het niet toepassen van bemesting, zoals in $54 \%$ van de onderzochte gevallen, en het voorkomen van fumonisinen in maïs ( $\mathrm{p}=$ $0,014)$. In $69 \%$ van de gevallen werd de hybride $6 \mathrm{I}_{4}$ (H 6I4) verbouwd. Van de $\mathrm{II}$ monsters die de grens van $\mathrm{I} 000 \mu \mathrm{g} / \mathrm{kg}$ overschreden, bleken er Io van de variëteit $\mathrm{H} 6 \mathrm{I}_{4}$ te zijn. In vergelijking met de fumonisinengehalten van niet gesorteerde maïs (94-21 $667 \mu \mathrm{g}$ / $\mathrm{kg}$, bleek dat gesorteerde maïs relatief gezien minder sterk gecontamineerd bleek door fumonisinen. Slechts 8 van de onderzochte stalen bleken gecontamineerd te zijn in een bereik van 24 tot I $758 \mu \mathrm{g} / \mathrm{kg}$. Deze resultaten suggereren dat door het adequaat sorteren van maïs een verminderde blootstelling aan fumonisinen kan gerealiseerd worden binnen de onderzochte leefgemeenschap.

Aan de hand van @Risk software werd de invloed van seizoensgebonden variatie in de fumonisinecontaminatie en van sortering onderzocht op de probabilistische blootstellinginschatting van fumonisinen bij peuters via de consumptie van maïs bevattende overgangsvoeding. Dit kon gerealiseerd worden door het combineren van de contaminatiedata van de oogsten van respectievelijk 2005 en 2006 en de beschikbare consumptiedata van de beschouwde peuters. Zoals aangetoond wordt in hoofdstuk 5 hadden de peuters in 2006 een aanzienlijker hoger risico [ $24 \%$ (95\% CI; 15-34)] om de PMDTI te overschrijden in vergelijking met de populatie die in hetzelfde jaar onderzocht werd maar gesorteerde maïs consumeerde [3\% (95\% CI; 2-I2)]. De $3 \%$ kans om de PMDTI te overschrijden in 2006 door de consumptie van overgangsvoeding op basis van gesorteerde maïs was dan weer significant kleiner dan de kans die de peuters in 2005 hadden om de referentiewaarde te overschrijden door consumptie van gesorteerde maïs [26\% $(95 \% \mathrm{CI}$; 23-30)]. Deze vaststelling onderstreept enerzijds het belang van seizoensgebonden variatie in de contaminatie van maïs met fumonisinen. Anderzijds werden de beperkingen die het uitsorteren van beschadigde of beschimmelde maïs bleek te hebben om dergelijke contaminatie terug te dringen, geïllustreerd. Ondanks het feit dat in 2005 de inschatting 
werd uitgevoerd op basis van de gesorteerde maïs bleek de blootstelling vergelijkbaar met deze in 2006 op basis van de contaminatiedata van niet gesorteerde maïs.

Er moet echter wel rekening gehouden worden met een mogelijke overschatting van de blootstellinginschatting aangezien de contaminatiegegevens waren gebaseerd op niet vermalen maïs. Het is immers bekend dat door het vermalen van maïs en meer specifiek door het verwijderen van de pel een gevoelige reductie kan bekomen worden in de fumonisinecontaminatie, zelfs indien de maïs niet wordt voorgesorteerd. Om te verhelpen aan dit euvel werd een nieuwe blootstellinginschatting uitgevoerd op basis van contaminatiedata die werden bekomen voor kant-en-klaar maïsmeel. Deze inschatting werd zowel deterministisch (hoofdstuk 6) als probabilistisch (hoofdstuk 7) uitgevoerd.

In hoofdstuk 6 werden de fumonisineconcentraties in 102 kant-en-klare maïsmeelstalen op een deterministische wijze gecombineerd met de maïs consumptiedata. Tevens werden deze data gecombineerd met de antropologische parameters om een verband te onderzoeken tussen de fumonisineblootstelling per individuele peuter en de groeiprestaties in de periode van 6 tot 12 maanden. Lengte voor leeftijd $z$-scores (LLZ), gewicht voor leeftijd $z$-scores (GLZ) en gewicht voor lengte $z$-scores (GLZ) werden berekend op basis van de internationale referentie mediaanwaarde zoals aanbevolen door de Wereldgezondheidsorganisatie in 2005. Dit onderzoek toonde aan dat van de 215 onderzochte peuters, 26 (ongeveer $12 \%$ dus) individuen werden blootgesteld aan fumonisinengehalten die de PMTDI van $2 \mu \mathrm{g} / \mathrm{kg}$ lichaamsgewicht overschreden. Bij een leeftijd van I2 maanden bleek dat het gemiddelde voor LLZ $\left(-1,5^{6} \pm \mathrm{I}, 00\right)$ van de peuters met een blootstelling lager dan de PMTDI significant hoger was $(\mathrm{p}<0,05)$ dan de respectievelijke waarde van $-2,18 \pm 1,04$ bekomen voor de peuters met een blootstelling hoger dan deze referentiewaarde. In het algemeen bleek fumonsineblootstelling significant negatief gecorreleerd te zijn met LGZ en GLZ $(p<0,05)$. Het risico op fumonisineblootstelling bij peuters werd ook op een probabilistische manier ingeschat. De resultaten van deze studie zijn weergegeven in hoofdstuk 7.

Dit hoofdstuk bespreekt verder op basis van een aantal hypothetische scenario's op basis van maïsconsumptie enerzijds en fumonisinecontaminatie van maïs anderzijds een aantal beleidsopties om de fumonisineblootstelling bij peuters via de consumptie van overgangsvoeding in te dijken en terug te dringen in de rurale gebieden van Tanzania. Gebaseerd op de blootstellinginschatting kon berekend worden dat de kans dat een peuter de PMTDI overschreed momenteel $15 \%$ bedraagt ( $95 \%$ CI; 10-19\%). Dit risico werd teruggedrongen door de maximum fumonisinecontaminatie te verlagen tot $150 \mu \mathrm{g} / \mathrm{kg}$ bij een constante maïsconsumptie of door de maïsconsumptie te verminderen tot $20 \mathrm{~g} /$ peuter/dag mits een maximum contaminatie van $\mathrm{I} 000 \mu \mathrm{g} / \mathrm{kg}$ gehanteerd zou worden. Rekening houdend met de economische en technische belemmeringen om goede landbouwkundige praktijken toe te passen in de rurale gebieden van Tanzania, is het wellicht praktisch onmogelijk om de fumonisinecontaminatie van maïs terug te dringen tot het hierboven genoemde niveau van $150 \mu \mathrm{g} / \mathrm{kg}$. Daarom suggereren de resultaten om een maximale limiet van I $000 \mu \mathrm{g} / \mathrm{kg}$ te hanteren betreffende de fumonisinecontaminatie van mais in Tanzania, hetgeen overeenkomt met de geldende Europese norm, in combinatie 
met een reductie van de maïsconsumptie tot op een niveau van $20 \mathrm{~g} /$ peuter/dag en dit door een evenredige vervanging van maïs door alternatieve graangewassen.

$\mathrm{Na}$ hoofdstuk 7 worden algemene conclusies, perspectieven en aanbevelingen voor toekomstig onderzoek geformuleerd. Als conclusie kan gesteld worden dat dit onderzoek heeft aangetoond dat fumonisinen en in mindere mate aflatoxinen in belangrijke concentraties worden teruggevonden in maïs zoals deze verbouwd wordt in de rurale gebieden van Tanzania. De fumonisinegehalten die werden teruggevonden in deze studie zijn vergelijkbaar met deze van andere studies op maïs uitgevoerd in andere Afrikaanse landen. Deze studie suggereert dat de variëteit $\mathrm{H}_{6} \mathrm{I}_{4}$ en het gebrek aan bemesting een impact hadden op de fumonisinecontaminatie van mais verbouwd in het Rombo district. Tevens werd aangetoond dat sortering van maïs zoals dit reeds door vele landbouwers gebeurt een maatregel is die kan helpen om de fumonisinecontaminatie terug te dringen.

Net zoals eerdere studies uitgevoerd in Zuid-Afrika toont dit onderzoek aan dat de algemene rurale populatie van Tanzania en de peuters in het bijzonder een groot risico lopen om blootgesteld te worden aan fumonisinen. De bevolking van de Kilimanjaro regio loopt bovendien een hoger risico om aan hoge gehalten fumonisinen blootgesteld te worden, omdat ze courant niet gepelde maïs bleken te consumeren, hetgeen in tegenstelling was met de populaties in de andere onderzochte regio's. Het risico is schrikbarend hoog bij peuters die niet gesorteerde maïs consumeren. Deze studie suggereert ook dat er een verband kan gevonden worden tussen groeiachterstand bij peuters en fumonisineblootstelling.

Het is duidelijk dat op basis van het maïsconsumptiepatroon voor aanvullende voeding in de rurale gebieden van Tanzania, het wenselijk zou zijn om een maximum contaminatie van $150 \mu \mathrm{g} / \mathrm{kg}$ te tolereren. Echter, gezien deze limiet in de praktijk onrealistisch laag ligt, wordt gesuggereerd de EU norm van I $000 \mu \mathrm{g} / \mathrm{kg}$ te hanteren in combinatie met een terugdringen van de maïsconsumptie tot $20 \mathrm{~g} /$ peuter $/ \mathrm{dag}$. Om het specifiëren van geschikte preventiestrategieën voor de gehele Tanzaniaanse populatie mogelijk te maken is echter meer onderzoek nodig, meer bepaald om (I) tussen de landbouwpraktijken die reeds van toepassing zijn deze te identificeren die het meest succesvol zijn om fumonisinecontaminatie te beperken, (2) in gecontroleerde omstandigheden na te gaan wat de mogelijkheden zijn van het sorteren en pellen van maïs, zoals reeds toegepast in bepaalde regio's om de fumonisinecontaminatie terug te dringen, (3) in te schatten wat de maïsconsumptie is in rurale en verstedelijkte gebieden van Tanzania zodat het ook mogelijk wordt om de blootstelling aan fumonisinen vollediger in kaart te brengen en (4) om alternatieve graangewassen te identificeren welke kunnen voorgesteld worden om er op een graduele manier maïs door te substitueren in overgangsvoeding om zodoende de fumonisineblootstelling tot een veilig niveau terug te dringen zonder evenwel de voedingswaarde te compromitteren. 